\title{
BUCCOADHESIVE TABLETS FOR DELIVERY OF VERAPAMIL HCI: DESIGN, IN-VITRO ANALYSIS AND IN-VIVO EVALUATION
}

\author{
Fakhr El Din S. Ghazy, Hanan M. El-Nahas, Mohamed A. Gad and Noura G. Eissa \\ Department of Pharmaceutics, Faculty of Pharmacy, Zagazig University, Zagazig, Egypt

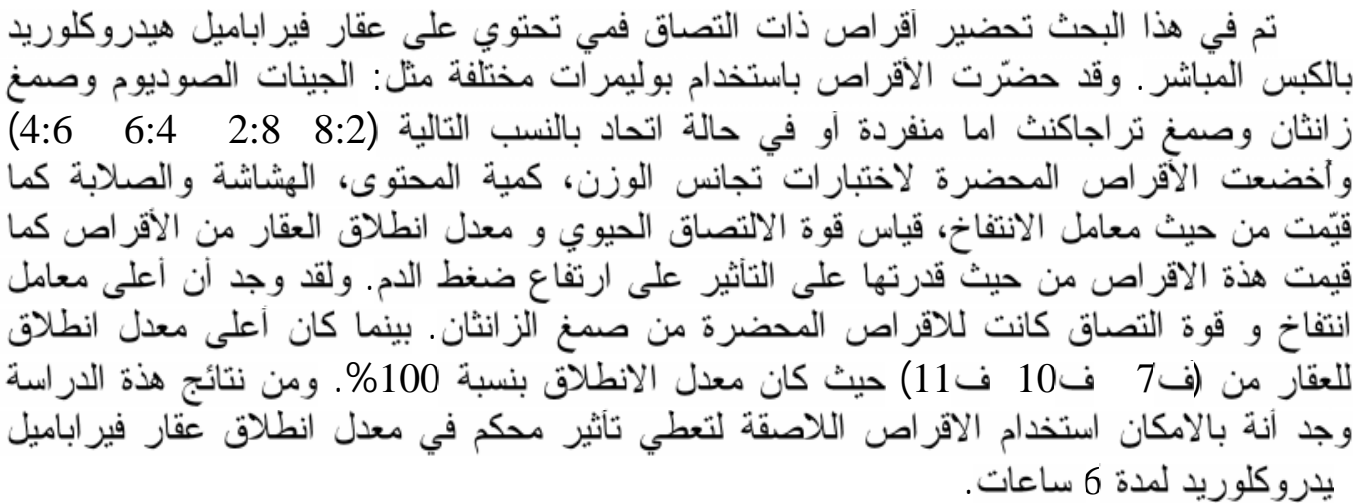

Buccoadhesive controlled release verapamil $\mathrm{HCl}$ tablets have been prepared using mucoadhesive polymers namely; sodium alginate (Na Alg), xanthan gum (XG) and gum tragacanth $(G T)$ either alone or in combination in different ratios 2:8, 8:2, 4:6 and 6:4. The prepared tablets were evaluated for their weight variation, thickness, hardness, friability and dissolution, content uniformity, swelling index, in-vitro adhesion, in-vitro drug release and invivo hypertension study. Tablets containing XG showed the highest swelling index and bioadhesive force. The maximum cumulative \% released (100\%) was observed in F7, F10 and F11 due to high percent of Na alg. The kinetics studies show that the release follows zero order kinetics except F1 that it obeyes a diffusion model. The buccoadhesive verapamil HCl tablet had suggested being promising for the transmucosal delivery of verapamil $\mathrm{HCl}$ and allowing a controlled drug delivery for 6 hrs.

\section{INTRODUCTION}

Oral mucosal drug delivery is a one of methods of systemic drug delivery that offers several advantages over both injectable and enteral methods. It enhances drug bioavailability because the mucosal surfaces are usually rich in blood supply, providing the means for rapid drug transport to the systemic circulation and avoiding, in most cases, degradation by first-pass hepatic metabolism ${ }^{1}$. The buccal mucosa is a useful route for the treatment of either local or systemic therapies overcoming the drawbacks of conventional administration routes. The buccal mucosa is relatively permeable, robust in comparison to the other mucosal tissues and is more tolerant to potential allergens which have a reduced tendency to irreversible irritation or damage. So, it has been largely investigated as a potential site for controlled drug delivery in various chronic systemic therapies ${ }^{1}$.

Hypertension or high blood pressure is a chronic medical condition in which the blood pressure in the arteries is elevated. It is classified as either primary (essential) or secondary. About $90-95 \%$ of cases are termed "primary hypertension", which refers to high blood pressure for which no medical cause can be found ${ }^{2}$. The remaining $5-10 \%$ of cases (Secondary hypertension) is caused by other conditions that affect the kidneys, arteries, heart, or endocrine system.

Persistent hypertension is one of the risk factors for strokes, heart attacks, heart failure and arterial aneurysm, and is a leading cause of chronic kidney failure ${ }^{3}$. Moderate elevation of arterial blood pressure leads to shortened life expectancy. Both dietary and lifestyle changes as well as medicines can improve blood 
pressure control and decrease the risk of associated health complications.

Verapamil hydrochloride is a calcium ion influx inhibitor (slow channel blocker or calcium ion antagonist). Which exerts its pharmacologic effects by modulating the influx of ionic calcium across the cell membrane of the arterial smooth muscle as well as in conductile and contractile myocardial cells. It is an arterial vasodilator with some venodilator effect, which has been used in the management of angina pectoris, essential hypertension and antiarrhythmia ${ }^{4}$.

Verapamil hydrochloride extendedrelease is available for oral administration as a 120, 180 and $240 \mathrm{mg}$ light green capsule shaped, scored, film-coated tablets. Because of rapid biotransformation of verapamil during its first pass through the portal circulation, bioavailability ranges from $20 \%$ to $35 \%$. Peak plasma concentrations are reached between 1 and $2 \mathrm{hrs}$ after oral administration.

For the mentioned reasons the study was developed to design the controlled release mucoadhesive tablets of verapamil $\mathrm{HCl}$ for buccal delivery to avoid the bypass effect of liver. Various formulations of verapamil $\mathrm{HCl}$, composed of different bioadhesive polymers, were developed and investigated for their physicochemical properties, such as weight variation, thickness, hardness, friability, content uniformity, swelling index, in-vitro bioadhesion strength, drug release and in-vivo hypertension study.

\section{MATERIALS AND METHODS}

\section{Materials}

Verapamil $\mathrm{HCl}$ was kindly supplied by Arabic. Drug Co., Cairo, Egypt. Sodium alginate (Memphis Co., Cairo, Egypt), Xanthan gum (Arabic. Drug Co., Cairo, Egypt), Gum tragacanth and magnesium stearate (El-Nile Co., Cairo, Egypt) and Crude porcine mucin was purchased from Sigma Co., USA.

\section{Equipments}

Spectrophotometer

(Schimadzu

Corporation, Japan), dissolution apparatus (Type PTWII, Pharma test, West Germany), Digital pH meter (JENCO, U.S.A), Thermostatic shaker water bath (Julabo SW-
20C, Germany), Single punch tablet machine fitted $10 \mathrm{~mm}$ flat faced punches and dies (Korsch Frogerais, type AO, Berlin, Western Germany), Pharma test tablet friabilator (Western Germany), Erweka tablet hardness tester (Erweka-Apparatabeller Frankfort, Western Germany), Polyethylene arterial cannula and Oscillograph (Washington, U.K).

\section{Preparation of buccoadhesive tablets}

The tablets were prepared by direct compression technique, homogeneously blending the polymers, $\mathrm{Mg}$ stearate and verapamil $\mathrm{HCl}$ (40 $\mathrm{mg} /$ tablet) in a mortar. The mixture was finally compressed to a flat-faced tablets (203 mg) using a single-punch tablet machine. The compression procedure was carried out manually. The constituents of each of the eleven formulations are presented in table 1 .

\section{Tablets evaluation}

All the prepared buccoadhesive tablets were evaluated for following parameters.

\section{Weight uniformity ${ }^{5}$}

Twenty tablets were individually weighed. The average weight was determined and the standard deviation was calculated.

\section{Thickness and diameter ${ }^{6}$}

The thickness and the diameter of three tablets from each formula (selected randomly) were measured by means of a micrometer caliper. The average thickness and diameters were determined.

\section{Hardness $^{7}$}

Hardness was measured using Erweka tablet hardness tester. For each batch two tablets were tested.

\section{Friability $^{8}$}

Friability test is performed to assess the effect of friction and shocks, which may often cause tablet to chip, cap or break. Five tablets were weighed and placed in the Pharm-test friabilator and apparatus was rotated at $25 \mathrm{rpm}$ for $4 \mathrm{~min}$. After revolutions the tablets were dusted and weighed again. The percentage friability was measured using the formula; the results are shown in table 2. 
Table 1: Composition of verapamil $\mathrm{HCl}$ buccoadhesive tablets.

\begin{tabular}{||l|c|c|c|c|c|c|c|c|c|c|c|}
\hline $\begin{array}{c}\text { Ingredients } \\
\text { (mg/tab) }\end{array}$ & F1 & F2 & F3 & F4 & F5 & F6 & F7 & F8 & F9 & F10 & F11 \\
\hline Verapamil HCl & 40 & 40 & 40 & 40 & 40 & 40 & 40 & 40 & 40 & 40 & 40 \\
\hline Na Alg & 160 & & & 32 & 64 & 96 & 128 & 32 & 64 & 96 & 128 \\
\hline XG & & 160 & & 128 & 96 & 64 & 32 & & & & \\
\hline GT & & & 160 & & & & & 128 & 96 & 64 & 32 \\
\hline Mg stearate & 3 & 3 & 3 & 3 & 3 & 3 & 3 & 3 & 3 & 3 & 3 \\
\hline Total & 203 & 203 & 203 & 203 & 203 & 203 & 203 & 203 & 203 & 203 & 203 \\
\hline
\end{tabular}

Table 2: Summary of tablet assay and physical evaluation.

\begin{tabular}{|c|c|c|c|c|c|c|}
\hline Formula & $\begin{array}{c}\text { Weight } \\
\text { Variation }\end{array}$ & $\begin{array}{c}\text { Thickness } \\
(\mathrm{mm})\end{array}$ & $\begin{array}{c}\text { Diameter } \\
(\mathrm{mm})\end{array}$ & $\begin{array}{c}\text { Hardness } \\
(\mathrm{Kp})\end{array}$ & $\begin{array}{c}\text { Tablet } \\
\text { Friability } \\
(\%)\end{array}$ & $\begin{array}{c}\text { Drug } \\
\text { content } \\
(\mathrm{mg})\end{array}$ \\
\hline F1 & $203.25 \pm 0.37$ & $2.26 \pm 0.04$ & $10.06 \pm 0.02$ & $5.74 \pm 0.33$ & 0.73 & $39.6 \pm 0.47$ \\
\hline F2 & $203.10 \pm 0.33$ & $2.47 \pm 0.03$ & $10.06 \pm 0.03$ & $6.33 \pm 1.28$ & 0.25 & $40.1 \pm 0.62$ \\
\hline F3 & $203.15 \pm 0.16$ & $2.49 \pm 0.03$ & $10.07 \pm 0.03$ & $5.52 \pm 0.16$ & 0.57 & $39.4 \pm 1.32$ \\
\hline F4 & $203.10 \pm 0.12$ & $2.42 \pm 0.03$ & $10.01 \pm 0.02$ & $6.35 \pm 0.57$ & 0.29 & $40.2 \pm 0.35$ \\
\hline F5 & $202.90 \pm 0.05$ & $2.37 \pm 0.03$ & $10.04 \pm 0.02$ & $5.93 \pm 0.63$ & 0.34 & $39.9 \pm 0.43$ \\
\hline F6 & $202.95 \pm 0.15$ & $2.35 \pm 0.03$ & $10.05 \pm 0.02$ & $5.50 \pm 0.36$ & 0.49 & $39.9 \pm 0.68$ \\
\hline F7 & $203.35 \pm 0.10$ & $2.34 \pm 0.04$ & $10.03 \pm 0.01$ & $5.21 \pm 0.50$ & 0.58 & $40.5 \pm 0.65$ \\
\hline F8 & $203.4 \pm 0.30$ & $2.43 \pm 0.02$ & $10.00 \pm 0.03$ & $6.73 \pm 0.38$ & 0.59 & $39.3 \pm 0.89$ \\
\hline F9 & $202.95 \pm 0.41$ & $2.42 \pm 0.03$ & $10.05 \pm 0.02$ & $5.75 \pm 0.22$ & 0.64 & $39.3 \pm 0.89$ \\
\hline F10 & $203.55 \pm 0.35$ & $2.34 \pm 0.04$ & $10.03 \pm 0.03$ & $5.69 \pm 0.24$ & 0.68 & $39.8 \pm 0.96$ \\
\hline F11 & $203.35 \pm 0.28$ & $2.37 \pm 0.03$ & $10.05 \pm 0.02$ & $5.20 \pm 0.28$ & 0.73 & $40.5 \pm 0.30$ \\
\hline
\end{tabular}

Mean $\pm \operatorname{SD}(n=3)$

$$
\% \mathrm{~F}=\left\{1-\left(\mathrm{W} / \mathrm{W}_{\mathrm{o}}\right)\right\} \times 100
$$

Where, $\% \mathrm{~F}=$ friability in percentage

$\mathrm{W}_{\mathrm{o}}=$ Initial weight of tablet

$\mathrm{W}=$ weight of tablets after revolution

\section{Content uniformity ${ }^{9}$}

Ten tablets of each formulation were ground in a mortar to a powder form. An accurately weighed amount of the powder, equivalent to $40 \mathrm{mg}$ of verapamil $\mathrm{HCl}$, was transferred to a $100 \mathrm{ml}$ volumetric flask. The powder was dissolved in distilled water using a magnetic stirrer. After filtration, the solution was assayed spectrophotometrically at $278 \mathrm{~nm}$ against distilled water as a blank (using drugfree samples). Calculation was made using a reconstructed calibration curve for the drug $(10-80 \mu \mathrm{g} / \mathrm{ml})$ in distilled water.

\section{Swelling study ${ }^{10}$}

Three randomly chosen tablets from each formula were glued to glass beads using cyanoacrylate glue. They were weighed $\left(\mathrm{W}_{1}\right)$ and placed separately in beakers containing 40 $\mathrm{ml}$ distilled water in a shaker at $100 \mathrm{rpm}$ at $37^{\circ} \mathrm{C}$. After $0.5,1,2,3$ and $4 \mathrm{hrs}$, remove the tablet (excess water should be removed) then reweighed it $\left(\mathrm{W}_{2}\right)$ and the swelling index was calculated using the following equation:

Swelling index $=\mathrm{W}_{2}-\mathrm{W}_{1} / \mathrm{W}_{1}$

\section{Surface pH study}

The surface $\mathrm{pH}$ of the tablets was determined in order to investigate the possibility of any irritation in the buccal mucosa. As an acidic or alkaline $\mathrm{pH}$ may cause irritation to the buccal mucosa, it was determined to keep the surface $\mathrm{pH}$ as close to neutral as possible. The method adopted by Bottenberg et al. ${ }^{11}$ was used to determine the surface $\mathrm{pH}$ of the tablet. A combined glass electrode was used for this purpose. The tablet was allowed to swell by keeping it in contact with $1 \mathrm{ml}$ of distilled water ( $\mathrm{pH} 6.5 \pm 0.05$ ) for 2 hrs at room temperature. The $\mathrm{pH}$ was measured 
by bringing the electrode in contact with the surface of the tablet and allowing it to equilibrate for $1 \mathrm{~min}$.

\section{Bioadhesion measurements}

The bioadhesive forces of the tablets were determined by measuring the force required to detach the tablet formulations from mucin tablet using a modified balance method as shown in figure $1^{12 \& 13}$.

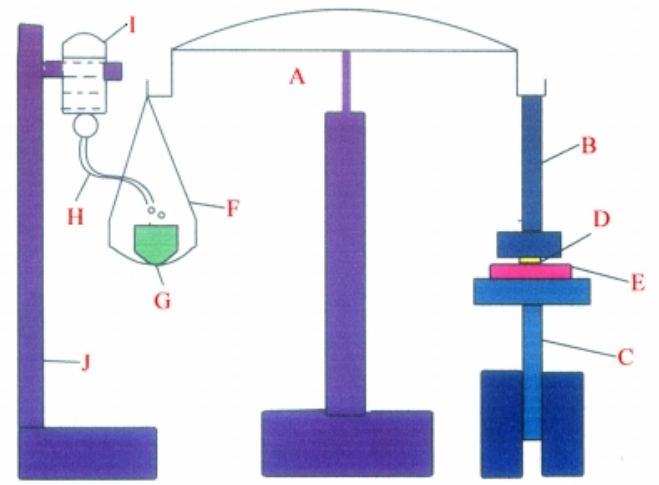

Fig. 1: Diagrammatic representation of the mucoadhesive force-measuring device ${ }^{14}$.

Initially mucin tablets were prepared by compression of crude porcine mucin in a single punch tablet machine using a flat punch of 10 $\mathrm{mm}$ diameter ${ }^{15}$. At the right arm of the balance (B), mucin tablet (E) was glued to moving lower platform (C) and tablet formulation (D) was glued to the upper clamp of the balance using cyanoacrylate glue. Prior to mucoadhesion testing, the mucin tablet and the buccal tablet were hydrated by distilled water. The lower stage $(\mathrm{C})$ was then elevated till the surface of the tablet contacted to the mucin tablet. A constant (preload) downward force of $10 \mathrm{gm}$ weight was then applied for $1 \mathrm{~min}$ and removed. On the other side of the used device, water was dropped from a glass bottle (I) through an infusion set $(\mathrm{H})$ into a plastic jar $(\mathrm{G})$ in the pan (F) at a constant rate of 60 drops/min. The addition of water was stopped when mucin tablet was detached from the buccoadhesive tablet. The minimal weight of water required to detach the buccoadhesive tablet from the mucin tablet was noted as the mucoadhesive force, and these experiments were done in triplicate.

Bioadhesive force or the detachment stress $\left(\right.$ dyne $\left./ \mathrm{cm}^{2}\right)$ was determined using the equation adapted by Ch'ng et al. ${ }^{16}$ where
Detachment force $\left(\right.$ dyne $\left./ \mathrm{cm}^{2}\right)=\mathrm{m} \mathrm{G} / \mathrm{A}$

Since $\mathrm{m}$ is the weight of water $(\mathrm{g}), \mathrm{G}$ is the acceleration due to gravity taken as $980 \mathrm{~cm} / \mathrm{s}^{2}$; $A$ is the area of the buccal tablet (area of contact).

\section{In-vitro release study}

Drug release studies $(\mathrm{n}=3)$ were conducted for all formulations using dissolution apparatus PTWII, (Paddle apparatus). Distilled water pH $6.5 \pm 0.05$ (500 $\mathrm{ml}$ ) was used as a release medium at $37 \pm 1^{\circ} \mathrm{C}$ at $50 \mathrm{rpm}$. Aliquots of $5 \mathrm{ml}$ samples were periodically withdrawn at $0.5,1,1.5,2,3,4,5$ and $6 \mathrm{hrs}$ and the sample volume was replaced with an equal volume of fresh dissolution medium. The samples were filtered and analyzed spectrophotometrically at $278 \mathrm{~nm}$. No interference occurred from the excipients.

\section{Data analysis of release study}

The data of drug release from the tested buccoadhesive tablets were subjected to theoretical analysis to determine the order of kinetic release according to the following equations:

$$
\text { Zero order kinetic } \mathrm{Q}=\mathrm{K}_{\mathrm{o}} \mathrm{t}
$$

Where, $\mathrm{Q}$ is the amount of drug release at time, $t$ and $K_{o}$ is the release rate constant.

First order kinetic $\log Q=\mathrm{K}_{1} \mathrm{t}$

Where $\mathrm{Q}$ is the percent of drug release at time, $t$ and $K_{1}$ is the release rate constant.

Higuchi Equation $\mathrm{Q}=\mathrm{K}_{2} \mathrm{t}^{1 / 2} 17$

Where, $\mathrm{Q}$ is the percentage of drug release at time $t$ and $K_{2}$ is the diffusion rate constant.

\section{In-vivo hypertension study}

In-vivo studies were done on the selected verapamil hydrochloride buccoadhesive tablet formulation (F7) which showed optimum bioadhesive force and in-vitro drug release to evaluate their efficiency in comparison to that given orally. Adult albino male rats weighing 200 250 gm each were utilized in this study.

Hypertension was induced in rats by complete left renal artery ligation according to the method described by Cangiano et al. ${ }^{18}$. Animals were divided into three groups each consisting of six rats $(n=6)$ :

Group (I): Control and received buccoadhesive tablets free from drug (control). 
Group (II): Received aportion of verapamil hydrochloride tablet (F7) containing $5 \mathrm{mg}$ drug orally after grind and dissolved in distilled water.

Group (III): Received aportion of verapamil hydrochloride buccoadhesive tablet (F7) containing $5 \mathrm{mg}$ drug as shown in figure 2 .

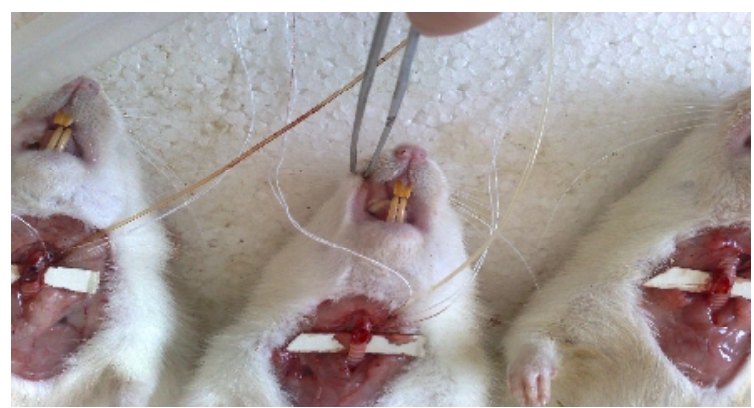

Fig. 2: Rat received verapamil hydrochloride buccoadhesive tablet.

The antihypertensive effect for the selected formula was studied after induction of hypertension and the results were compared to that of control (group I). The antihypertensive activity was studied at different time intervals $(1,2,3,4,5$ and $6 \mathrm{hrs})$ to differentiate between the onset of action of the oral and buccal route of administration. The animals were treated according to Ethical committee of animal handling in Zagazig University "ECAHZU").

\section{RESULTS AND DISCUSSION}

The percentage weight variations of all tablets were found to be in the range of 202.90 to $203.55 \mathrm{mg}$ (Table 2). All of the samples exhibited weight variation that was $\leq 1 \%$ of the 203-mg ideal tablet weight, well within USP guidelines.

The thickness of the prepared tablets varies from 2.26 to $2.49 \mathrm{~mm}$ (Table 2). All the formulations showed uniform thickness and low standard deviation confirms uniformity of prepared mucoadhesive tablets.

The diameter of the prepared tablets varies from 10.01 to $10.07 \mathrm{~mm}$ (Table 2). All the formulations showed uniform diameter.

The hardness of tablets ranged between 5.20 to $6.73 \mathrm{KP}$ (Table 2). This ensures good handling characteristics for all formula. The friability of all samples was $<1 \%$. Usually tablet friability relates inversely to tablet hardness, this suggests that all tablets were mechanically stable and exhibited acceptable tablet physical characteristics.

The drug content of all the formulation was found to be varied between 39.26 and $40.53 \mathrm{mg}$ (98.15 and 100\%) of verapamil $\mathrm{HCl}$, it complies with official specifications (Table 2).

The swelling index was calculated with respect to time (Fig. 3). It decreases gradually in the following order $\mathrm{XG}>\mathrm{Na}$ alg $>\mathrm{GT}$. Results showed that upon addition of $\mathrm{Na}$ alg to $\mathrm{XG}$, the swelling of the tablets decreased with increasing the concentration of $\mathrm{Na}$ Alg. On the contrary, increasing the concentration of $\mathrm{Na}$ alg in a mixture of $\mathrm{Na}$ alg and GT was accompanied by an increase in the swelling index values (Figs. $4 \& 5$ ). This is may be due to the hydrophilicity nature of the polymer that increasing the hydrophilicity leading to increase in the water uptake. It is noteworthy that the swelling index of the tablets prepared with polymer combination seemed to be an intermediate value between those of each polymer alone ${ }^{19}$.

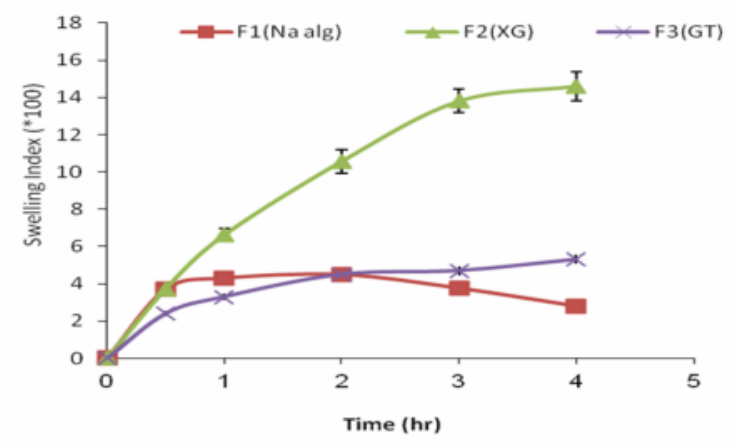

Fig. 3: Swelling index versus time profiles of verapamil hydrochloride buccoadhesive tablets containing single polymer.

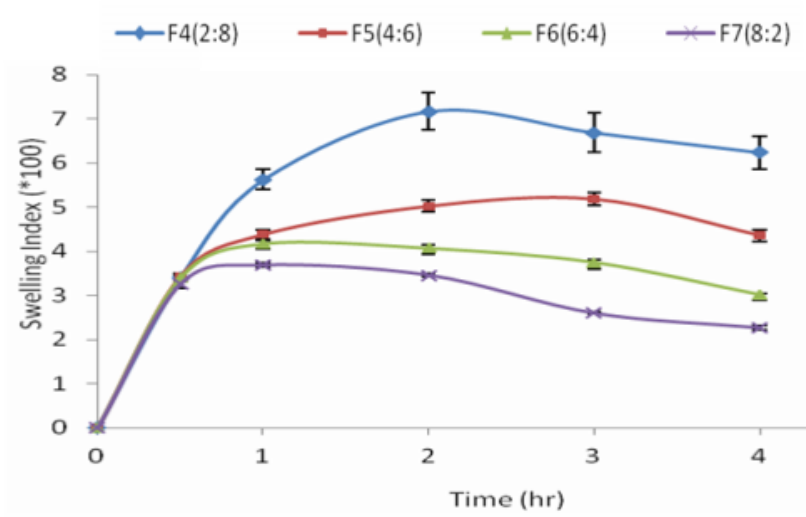

Fig. 4: Swelling index versus time profiles of verapamil $\mathrm{HCl}$ buccoadhesive tablets containing $\mathrm{Na}$ alginate $\&$ xanthan gum. 


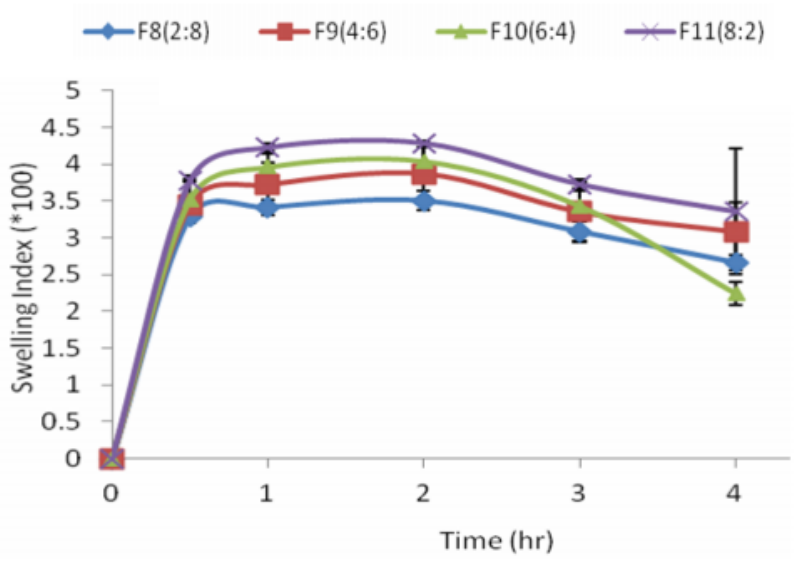

Fig. 5: Swelling index versus time profiles of verapamil $\mathrm{HCl}$ buccoadhesive tablets containing $\mathrm{Na}$ alginate \& Gum tragacanth.

The bioadhesion characteristics were affected by the type and combination of the polymers. Tablets containing XG showed higher bioadhesive force than those containing $\mathrm{Na}$ alg and GT as shown in (Fig. 6). Tablets containing XG had a faster hydration rate and achieved maximum swelling at a shorter period which could promote interpenetration of the polymer chains with the tissue. $\mathrm{Na}$ alg polymer contains greater portion of hydroxyl groups can provide the ability to form hydrogen bonds and could bind more strongly with oligosaccharide chains of $\operatorname{mucin}^{16}$. Therefore the higher bioadhesion performance of negatively charged polymers may be related to their good balance between available hydrogen bonding sites and an open expanded conformation ${ }^{20}$. In tablets containing mixtures of $\mathrm{Na}$ alg together with $X G$ and GT, increasing the concentration of $\mathrm{XG}$ and GT was accompanied by an increase in the bioadhesive force (Figs. $7 \& 8$ ).

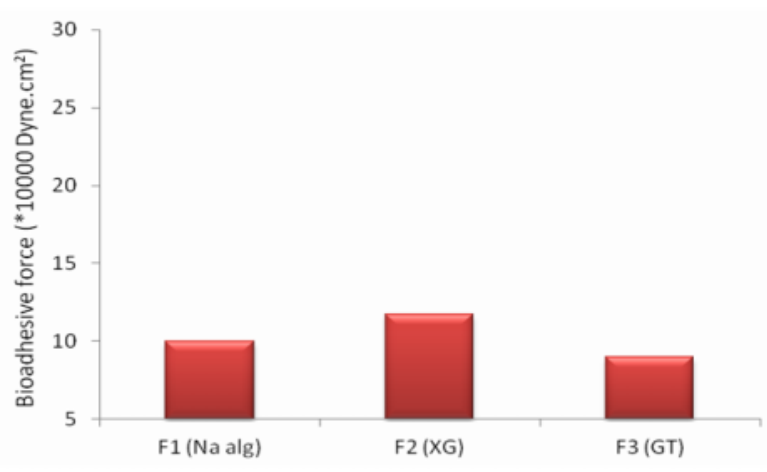

Fig. 6: Bioadhesive forces of verapamil hydrochloride buccoadhesive tablets containing single polymer.

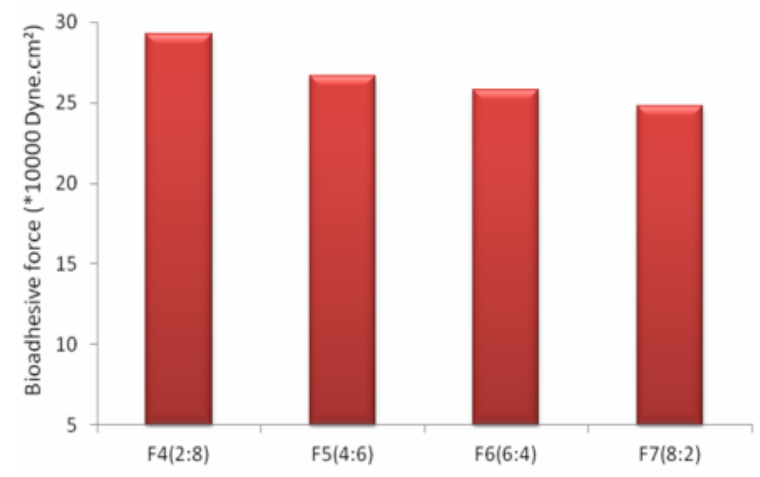

Fig. 7: Bioadhesive forces of verapamil hydrochloride buccoadhesive tablets containing sodium alginate and xanthan gum.

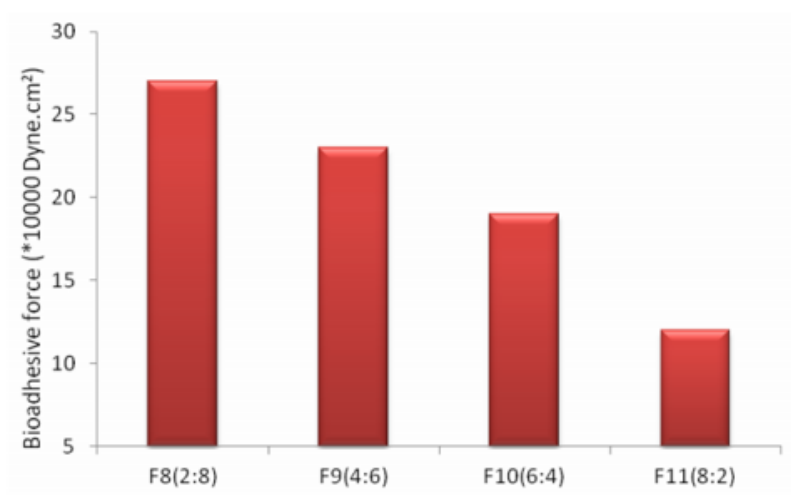

Fig. 8: Bioadhesive forces of verapamil hydrochloride buccoadhesive tablets containing sodium alginate and xanthan gum.

\section{In-vitro release study}

The release results of verapamil hydrochloride from the different bioadhesive tablets prepared are shown in (Figs. 9, 10 \& 11) respectively.

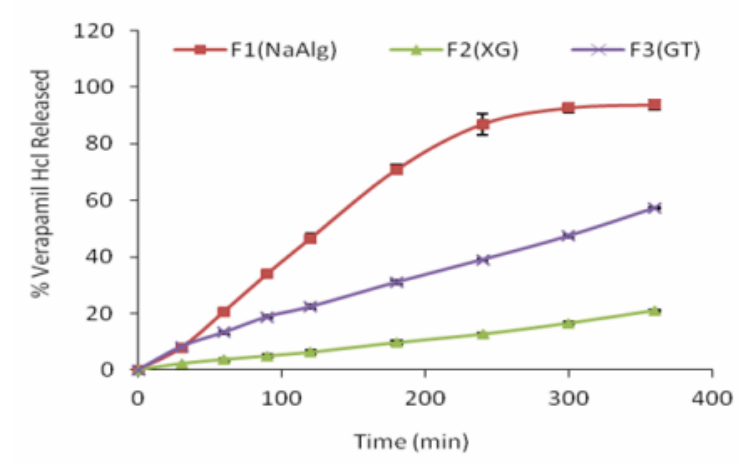

Fig. 9: In-vitro release profiles of verapamil hydrochloride from buccoadhesive tablets containing single polymers. 


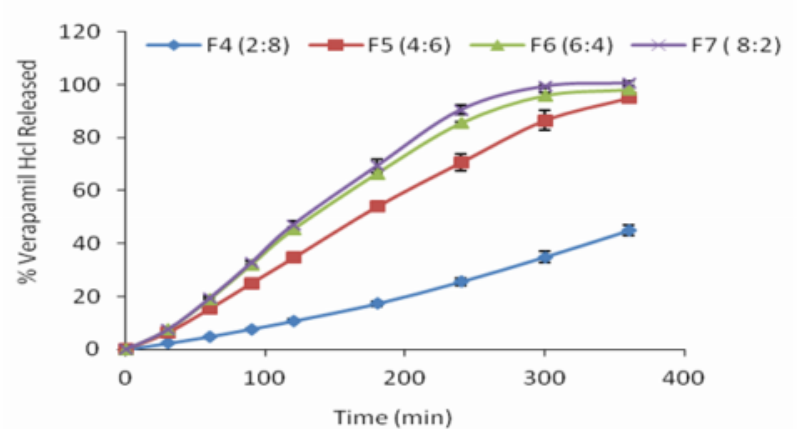

Fig. 10: In-vitro release profiles of verapamil hydrochloride buccoadhesive tablets containing $\mathrm{Na}$ alg \& XG.

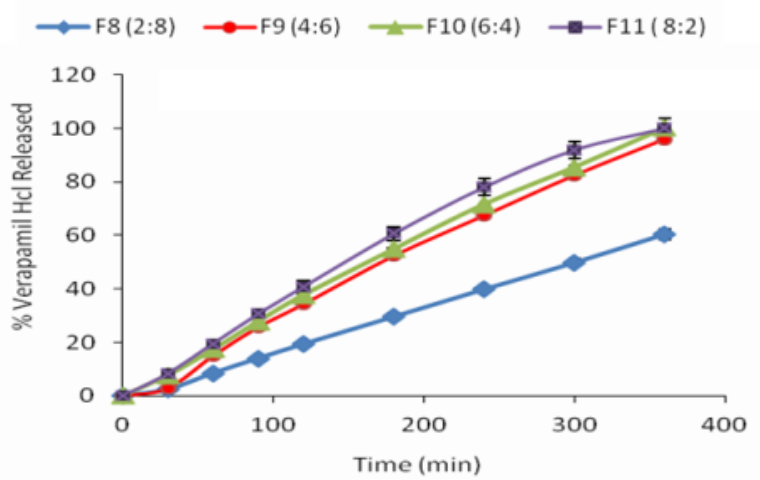

Fig. 11: In-vitro release profiles of verapamil hydrochloride buccoadhesive tablets containing $\mathrm{Na}$ alg \& GT.

The rank order for drug release for the different formulations was as follows: $\mathrm{F} 1>\mathrm{F} 3>\mathrm{F} 2$. It is evident that polymers with higher swelling properties showed the highest rate and extent of drug release except for tablets containing XG. The slow release of XG may be attributed to that the gel formed consists of closely packed swollen particles. With further increase in polymer amount, thicker gel forms inhibiting water penetration more strongly, resulting in significant reduction in the values of release indicating slower drug release. This is in agreement with the results obtained from ${ }^{21 \& 22}$ who findings that the viscosity of the gel layer around the tablet increases with increase in the hydrogel concentration, thus limiting the release of active ingredient. For the other formulae, higher swelling of the tablets gives less compact polymer which allows diffusion of verapamil hydrochloride from the polymer network easily ${ }^{23}$. It is anticipated that the high amount of water uptake by $\mathrm{Na}$ alg may lead to considerable swelling of the polymer matrix, allowing the drug to diffuse at a faster rate. GT showed moderate swelling and as a result showed moderate release.

In tablets containing polymer combinations, $\mathrm{Na}$ alg significantly increased the release rate of the drug when present in combination with XG and GT This may be attributed to the high swelling characters of these anionic polymers, where the use of different polymers in matrix formulations were reported to have a different influence on the rate of tablet erosion and swelling due to variations in the disruption of polymer networks at different times and rates ${ }^{24}$.

In order to determine the model which describes the pattern of drug release, the invitro release data were analyzed according to zero order, first order and Higuchi model.

The drug release was proceeded according to zero order kinetics in all of the formulae except F1 obey a Higuchi diffusion model.

\section{In-vivo study}

The surface $\mathrm{pH}$ of buccal tablets was found to be within $7 \pm 0.5$ unit of the neutral $\mathrm{pH}$, and hence these buccal tablets cannot cause any irritation in the buccal cavity.

Figure 12 shows that both group II and III showed a significant decrease in blood pressure compared to group I at all time intervals. The one way ANOVA test revealed that the difference between the antihypertensive effect of verapamil $\mathrm{HCl}$ in both oral and buccal group was statistically significant at $(\mathrm{P}<0.05)$ when compared to control group at all time intervals of the experiment. Group II receiving oral dose showed a sharp decrease in blood pressure after one hour.

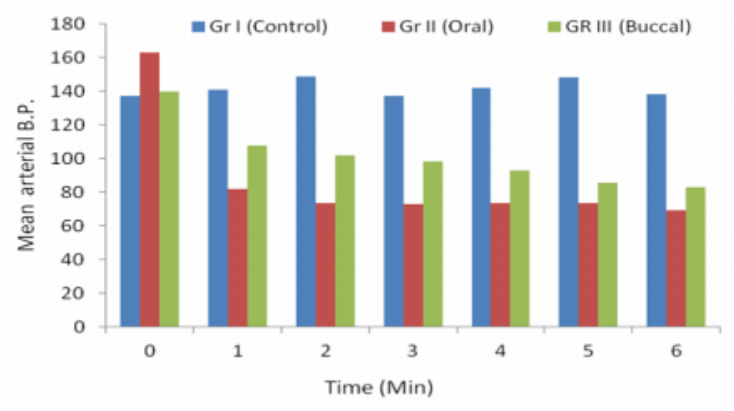

Fig. 12: Mean arterial blood pressure of different animal groups $(n=6)$.

Group I: control group

Group II: group received oral dose

Group III: group received buccal dose 
The one way ANOVA test showed a statistical significance $(\mathrm{P}<0.05)$ between oral group and buccal group for the first two hours. Meanwhile, no statistical significance $(\mathrm{P}<$ 0.05) was observed between the two groups after three hours till the end of the experiment. This reveals that the buccal tablets can give comparable results to oral tablets and reveals that buccal tablets gives sustained effect.

\section{Conclusion}

It was clear and evident from the results that mucoadhesive tablet prepared from the $\mathrm{Na}$ alg and XG in F7 proved to be promising for the trans-mucosal delivery of verapamil hydrochloride. The buccoadhesive tablet exerts comparable pharmacological action after $6 \mathrm{hrs}$ from oral drug administration allowing for controlled drug delivery along this period.

\section{REFERENCES}

1- N. V. S. Madhav, A. K. Shakya, P. Shakya and K. Singh, "Orotransmucosal drug delivery systems: A review", J. Control. Rel., 140, 2 (2009).

2- O. A. Carretero and S. Oparil, "Essential hypertension. Part I: definition and etiology", Circulation, 101 (3), 329 (2000).

3- S. D. Pierdomenico, M. Di Nicola, A. L. Esposito, R. Di Mascio, E. Ballone, D. Lapenna and F. Cuccurullo, "Prognostic value of different indices of blood pressure variability in hypertensive patients", Am. J. Hypertension, 22 (8), 842 (2009).

4- D. R. Laurence, P. N. Bennett and M. J. Brown, "Clinical Pharmacology", Eighth Edition. New York, Edinburgh, London and Tokyo, 1997, p. 425.

5- C. V. S. Subrahmanyam, "Text Book of Physical Pharmaceutics", $2^{\text {nd }}$ ed. New Delhi Vallabh Prakashan, 2001, p. 253.

6- United States Pharmacopeia, XXIV NF 19, United State Pharmacopia Convention, Rockville, 2000, p. 2388.

7- S. Gilbert, R. Banker and Neil, L. Anderson Lachman, H. A. Liberman and J. L. Knaig, Eds., "The Theory and Practice of Industrial Pharmacy", $3^{\text {rd }}$ edn, Varghese Publishing House, Bombay, 1990, p. 293.
8- S. A Sreenivas and A. P. Gadad, "Formulation and evaluation of ondancetron $\mathrm{HCl}$ directly compressed mouth disintegrating tablets", Indian Drugs, 43 (1), 35 (2006).

9- R. K. Nisreen Hassan, Khar, Mushir Ali and Javed Ali, "Development and evaluation of buccal bioadhesive tablet of an anti-emetic agent ondansetron", AAPS PharmSciTech., 10 (4), 1085 (2009).

10- Noha Adel Naffee, Fatma Ahmed Ismail and Nabila Ahmed Boraje, "Mucoadhesive delivery systems. II formulation and in-vitro / in-vivo evaluation of buccal mucoadhesive tablets containing water soluble drugs", Drug Development and Industrial Pharmacy, 30 (9), 995 (2004).

11- P. Bottenberg, R. Cleymaet, C. D. Muynek, J. P. Remon, D. Coomans and D. Slop, "Development and testing of bioadhesive, fluoride-containing slowrelease tablets for oral use", J. Pharm. Pharmacol., 43, 457 (1991).

12- A. El-Kamel, M. Sokar, V. Naggar and S. Al-Gamal, "Chitosan and sodium alginatebased bioadhesive vaginal tablets", AAPS PharmSciTech., 4 article 44, (2002).

13- K. G. H. Desai and T. M. P. Kumar, "Preparation and evaluation of a novel buccal adhesive system", ibid., 5 article 35 (2004).

14- S. M. Abdel-Hamid, S. E. Abdel-Hady, A. A. El-Shamy and H. F. El-Dessouky, "Formulation of an antispasmodic drug as topical local anasethetic", Int. J. Pharm., 326, 107 (2006).

15- D. S. Jones, A. D. Woolfson, A. F. Brown, W. A. Coulter, C. McClelland and C. R. Irwin, "Design, characterisation and preliminary clinical evaluation of a novel mucoadhesive topical formulation containing tetracycline for the treatment of periodontal disease", J. Control. Release, 67 (2-3), 357 (2000).

16- H. S. Ch'ng, H. Park, P. Kelly and J. R. Robinson, "Bioadhesive polymers as platforms for oral controlled drug delivery II: Synthesis and evaluation of some swelling, water-insoluble bioadhesive 
polymers", J. Pharm. Sci., 74 (4), 399 (1985).

17- W. I. Higuchi, "Analysis of data on the medicament release from ointments", ibid., 51, 802 (1962).

18- J. L. Cangiano, C. Rodriguez-Sargnt and M. Martinez-Maldonado, "Effects of antihypertensive treatment on systolic blood pressure and renin in experimental hypertension in rats", J. Pharmacol. Exp. Ther., 208 (2), 310 (1979).

19- M. I. Mohamed and S. Mansour, "Studies on bioadhesive vaginal tablets of econazole nitrate", Egypt J. Biomed. Sci., 19, 25 (2005).

20- U. Bertram and R. Bodmeier, "In-situ gelling, bioadhesive nasal inserts for extended drug delivery: In-vitro characterization of a new nasal dosage form", Eur. J. Pharm. Sci., 27, 62 (2006).
21- J. L. Ford, M. H. Rubinstein and J. E. Hogan, "Formulation of sustained release promethazine hydrochloride tablets using hydroxypropylmethyl cellulose matrices", Int. J. Pharm., 24, 327 (1985).

22- M. J. Vazques, B. Perez-Marcos, J. L. Gomez-Amoza, R. Martinez-Pacheco, C. Souto and A. Concheiro, "Influence of technological variables on release of drugs from hydrophilic matrices", Drug Dev. Ind. Pharm., 18, 1355 (1992).

23- S. Charde, M. Mudgal, L. Kumar and R. Saha, "Development and evaluation of buccoadhesive controlled release tablets of lercanidipine", AAPS PharmSciTech., 9, 182 (2008).

24- S. M. Khamanga and R. B. Walker, "Evaluation of rate of swelling and erosion of verapamil (VRP) sustained release matrix tablets", Drug Dev. Ind. Pharm., 32, 1139 (2006). 